\title{
Reduction of Wind Velocity Blowing Through Garden Plant into the Building
}

\author{
Nareerat Bourbud, and Kua-anan Techato*
}

\begin{abstract}
The research had attempted to find out the good setting of garden plant to be used as the decoration beside the corridor of the hospital. Many hospitals in Thailand have encouraged from the policy makers to increase the green area to relax the eye sight of both patient and their relatives. The increasing at the same time can blocked the wind passing through the patient room. The study of thermal comfort from various sources mentioned that the range of wind velocity for thermal comfort is $0.25-3 \mathrm{~m} / \mathrm{s}$ together with the ambient temperature of 22-36 degree Celsius. Many kinds of plant will be used in the experiment. The velocity of wind behind the plant will be measured to know if the blocking of plant is too much to create the thermal comfort for people in patient room. Finally the guideline of plant setting can be issued to the decorator that how to set the garden plant in term of width, height, and leave area.
\end{abstract}

Keywords - wind velocity, garden tree, building.

\section{INTRODUCTION}

$\mathrm{M}$ OST of the urban constructed buildings in Thailand now are designed with the air-conditioning system because of the hot and humid climate. The thermal comfort zone is the required condition which consumed energy. More than 50\% of energy consumption in the building is from the airconditioning system.[1] The passive design or design without the energy consumption for the comfort zone would help in the reverse of thinking.[2]

One of the contexts in passive design for comfort zone is the attempt to increase the natural ventilation in the building. [3] At the same time, some other green concept would lead to the opposite result of good ventilation. The promotion of having more plants as green area by growing the plant at the opposite site of patient room can block wind crossing the walk way. The good point is the view of green area but it would also reduce the natural ventilation or block the wind velocity from outside the building. The research therefore investigate the appropriate of bush or garden plant setting at balcony or the side row of the walk way in front of the patient room in hospital

\section{METHODOLOGY}

2.1 Plant Sansevieria spp. (see Figure 1) in the prepared bucket. Each type of plant will be varied at 20 and $30 \mathrm{~cm}$. Each height of plant will be varied the setting in double row and single row.

Nareerat Bourbud, and Kua-anan Techato* are with Faculty of Environmental Management, Prince of Songkla University

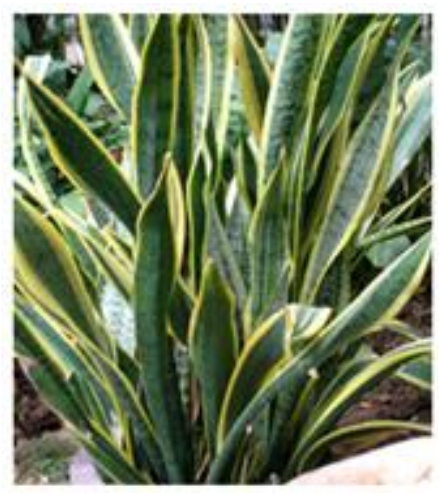

Fig. 1: Sansevieria spp.

2.2 The experiment will be taken with the $120 \mathrm{~cm}$ length of the building. The leave area index will be calculated for each experiment by Canon EOS 600D and passed to the Photoshop Software.

2.3 The wind velocity and humidity will be measured before enter to the room. The source of wind in the experiment will be the electric fan. The range of wind speed will be varied by starting from $0.25 \mathrm{~m} / \mathrm{s}$ to $3 \mathrm{~m} / \mathrm{s}$. The temperature and humidity will be measured for a month in summer and a month in raining season.

\section{RESUlt AND DISCUSSION}

From growing the Sansevieria spp at the corridor of the inpatient room in the hospital and setting source of the wind for experiment, it was found that the higher will block the wind blowing compared to the lower height of plant. The arrangement of the plant in double rows blocked the wind more than the single row. The zigzag will be test to see the result in the future. Some other plant types will also be tested in order to see the effect from the leaves.

\section{CONCLUSION}

The growing of garden plant at the corridor will increase the green area and nice look for the building but also block the wind blowing into the patient room. The arrangement of the plant can help reduce the blocking and maintain the thermal comfort. The plant type might be a factor associate the thermal comfort.

\section{ACKNOWLEDGMENT}

This Research was supported by Faculty of Environmental Management, Prince of Songkla University. 


\section{REFERENCES}

[1] Givoni, B. 1998. Climate consideration in building and urban design. New York: John Wiley \& Sons.

[2] Auliciems, Andris and V.Szokolay. 1997. Thermal Comfort. Brisbane. The University of Queensland Printery.

[3] Khedari, J., Yamtraipat, N., Pratintong, N., Hirunlabh, J. 2000. Thailand ventilation comfort chart.Energy and Buildings. 32: 245-249. http://dx.doi.org/10.1016/S0378-7788(00)00050-5 